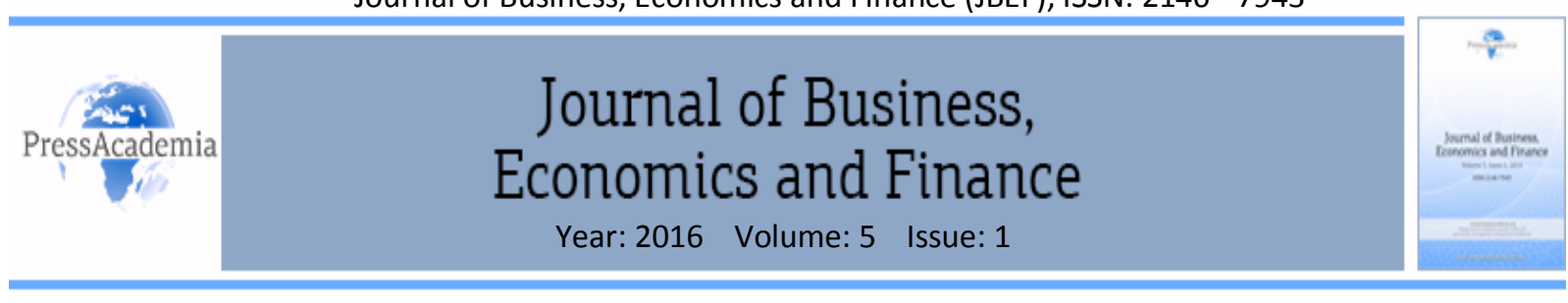

\title{
STOCHASTIC FRONTIER ANALYSIS OF HOSPITAL EFFICIENCY: DOES THE MODEL SPECIFICATION MATTER?
}

\section{DOI: 10.17261/Pressacademia.2016116550}

\author{
Emre Atilgan ${ }^{1}$ \\ ${ }^{1}$ Trakya University, Turkey. emreatilgan@trakya.edu.tr
}

\begin{abstract}
In this study, the technical efficiency of outpatient service production of hospitals is analyzed by using the Stochastic Frontier Analysis (SFA) with different model specifications. The purpose of the study is to present the effects of different SFA model specifications on the distribution of efficiency score and/or production function parameter estimates. In the analysis, the data of 429 Turkish MoH hospitals for the years 2012, 2013 and 2014 is used. The results of this paper suggest that different SFA specification, i.e. using Cobb-Douglas or Translog production technology and/or using an error component model or technical efficiency effects model, shifts the production function parameter estimates and the mean efficiency scores. On the other hand, the efficiency scores estimated by different model specifications are found to be highly correlated both in magnitude and rank order.
\end{abstract}

Keywords : Stochastic Frontier Analysis, Hospital Efficiency, Technical Efficiency, Outpatient Services, Production Function JEL Classification : D22, D24, 111

\section{INTRODUCTION}

In recent years, the hospital efficiency analysis has become a popular subject for both researchers and policy makers. Turkey Ministry of Health $(\mathrm{MoH})$ has introduced a new hospital management system in the final leg of the Health Transformation Program (HTP) with new tools for hospital performance assessment. The recent vintage was the enactments of the Public Hospital Associations (PHA), which are basically the regional hospital unions that were announced in 2011 and have been in operation since fall 2012.

This new management model introduced a new performance assessment policy for the PHAs and affiliated hospitals. The Turkish Public Hospitals Institution (PHI), which is the highest institution that rules all the public hospitals, has begun to use a Balanced Score Card approach to assess the managerial performance of the PHAs. In this assessment model, production efficiency scores of hospitals, which are estimated using the Stochastic Frontier Analysis (SFA) became a key factor. The efficiency scores are began to be estimated in four dimensions; that is hospital's outpatient, inpatient, surgery and emergency service productions. With respect to efficiency scores taken from those four different service production, hospital administrators are reviewing contracts or in case of poor performance scores, their contracts are terminated (Atilgan, 2015).

There is a debate in literature that whether the parametric techniques like SFA or the non-parametric techniques like Data Envelopment Analysis (DEA) is appropriate to analyze hospital efficiency. DEA attempts to determine the absolute economic efficiency of organizations against some imposed benchmark, and seeks to evaluate the efficiency of an organization relative to other organizations in the same industry (Worthington, 2004). The ease of implementation of DEA, given its nonparametric basis, substantial freedom is given on the specification of inputs and outputs, the formulation of the production correspondence relating inputs to outputs, and so on (Worthington, 2004), makes the method preferable for the researchers. On the other hand, SFA has an advantage that lies in the fact that it introduces a term representing noise, measurement error, and exogenous shocks beyond the control of the production unit, which is not predictable in DEA. This, in turn, 
allows the decomposition of deviations from the efficient frontier into two components, inefficiency and noise. Thus, SFA provides an objective way of determining the best practices by calculating a theoretical best-practice frontier (instead of one based on actual firms, as in DEA) and locating firms with respect to that frontier (Rosko and Mutter, 2008). Besides these advantages, SFA has some drawbacks that it requires more structured information, i.e. information about the production/cost technology, distributional assumptions for inefficiency term etc. and therefore the results of SFA is dependent on model specifications. With this regard, the assessment of PHAs and affiliated hospitals could also be affected by SFA model specification.

In this study, the technical efficiency of outpatient care production of hospitals is analyzed by SFA with different model specifications in order to present the effects of different SFA model specifications on the distribution of efficiency score and/or production function parameter estimates. With the results of the study, it is aimed to suggest a theoretical information for policy makers and researchers on appropriate hospital efficiency assessment.

The rest of the paper is organizes as follows. In the second section a brief literature review on SFA model specification is given. In section three, research design and methods are introduced with the model specifications and the data used in the analysis. In the section four, the results of the estimations are given. Then the paper concludes with discussions.

\section{LITERATURE REVIEW}

Inefficiency of a firm is determined by the deviations from the firm's production and/or cost frontiers. Econometric measurement of the inefficiency is then related with the estimation of that deviation. The parametric methods developed prior to SFA, like the deterministic model of Aigner and Chu (1968), Winsten's (1957) Adjusted Ordinary Least Squares method, Afriat's (1972) and Richmond's (1974) Adapted Ordinary Least Squares method, associated the inefficiency with all the deviations from the specified production limits. The main shortcoming of these approaches is they assume that the frontier is not affected by random cases. Stochastic Frontier Analysis was developed independently by Aigner et al. (1977) and Meeusen and Van den Broeck (1977) in order to overcome the main shortcoming of previous efficiency estimation methods. The purpose of SFA is to decompose variations from the best practice production/cost frontier into a random or classical error and a deterministic error, which is assumed to represent production/cost inefficiency.

Since the abovementioned pioneer studies of SFA, some other special cases of SFA empirical models are developed. As broadly described by Coelli et al. (2005) and Kumbhakar and Lovell (2000), an SFA empirical model may vary in five major ways: i. choice of cost function, ii. assumptions about the distribution of the composed error, iii. inclusion and exclusion of variables, iv. use of one-stage or two-stage estimation approach, v. use of cross-section or panel estimation technique.

The basic SFA specification, which decompose variations from the best practice production/cost frontier into a random or classical error and inefficiency, is so called as the Error Components (EC) model. The error components model with panel data, i.e. Battese and Coelli (1992) model, is as follows:

$Y_{i t}=X_{i t} \beta+\left(V_{i t}-U_{i t}\right)$

Where $i=1, \ldots n$ represent the $\mathrm{i}^{\text {th }}$ firm and $t=1, \ldots N$ represents the time, $Y_{i t}$ and $X_{i t}$ are respectively the output and inputs of the $\mathrm{i}^{\text {th }}$ firm; $\beta$ is the unknown parameters. In the Equation (1), $V_{i t}$ is the random error assumed to be distributed $V_{i} \sim$ iid $N\left(0, \sigma_{v}^{2}\right)$ and $U_{i t}=U_{i} \exp (-\eta(t-T)$ represents the inefficiency of the firm where $U_{i}$ are assumed to be distributed as $U_{i} \sim i i d N\left(\mu, \sigma_{U}^{2}\right)$.

The general specification of error component SFA model can be described as special cases by imposing restrictions to the model in Equation (1). Imposing restrictions to the distribution of inefficiency part of the composite error term or/and using panel data are also practicable. The composite error term could be assumed to have a half-normal distribution, gamma (Greene, 1980a, 1980b) and a more general distribution such as the truncated normal (Stevenson, 1980) in SFA studies. The general specification of error component SFA model can be described as special cases by imposing restrictions to the model in Equation (1). By restricting $\eta=0$, the time invariant models of Battese and Coelli (1988) (balanced panel data) and Battese, Coelli and Colby (1989) (unbalanced panel data) can be obtained. The restriction of $\mu=0$ with the aforementioned assumptions, gives 
the Pitt and Lee (1981) model specification.

The other well-known SFA specification is the Technical Efficiency (TE) effects model of Battese and Coelli (1995), in which both the efficiency scores of the firms and the firm-specific variables which may influence the firms' efficiency scores can be estimated in one-step. The SFA production function of TE effects model is as described in Equation (1). The difference of TE model from EC model is, in TE model the inefficiency term $U_{i t}$ is assumed to be distributed as $U_{i t} \sim N\left(m_{i t}, \sigma_{u}^{2}\right)$, where $m_{i t}=z_{i t}^{\prime} \delta+e_{i}$ and $z_{i t}^{\prime}$ is a vector of variables which may influence the efficiency of a firm, $\delta$ is a vector of parameters to be estimated.

As of now, there are no theoretical reasons for the selection of distributional forms for $u$. While Coelli et al. (2005) indicate that the truncated normal distribution assumption has a potential to partially alleviate the distribution problem, Rosko (2001) and Rosko and Mutter (2008) both reported that varying assumptions about the distribution of the deterministic error has had little impact on estimated inefficiencies in health care inefficiency literature.

SFA empirical models also vary by production/cost technology definitions. Hospital production efficiency estimation with SFA requires the estimation of the production function, thus the functional form or the technology of the production frontier has to be defined. In the hospital SFA efficiency studies, the production/cost function technology definition range from Homothetic function (Folland and Hofler, 2001), Leontief (Li and Rosenman, 2001), Box-Cox transformed stochastic frontier (Linna, 1998) and Ad-Hoc functions (Chirikos, 1998/1999; Chirikos and Sear, 2000), to more common and mainly used forms like Translog (Chirikos, 1998; Deily et al., 2001; Deily and McKay, 2005,2006; McKay et al., 2002/2003; Rosko, 1999, 2001a, 2001b, 2003; Rosko and Chillingerian, 1999; Rosko and Proenca, 2005; Zuckerman et al., 1994) and CobbDouglas (Carey, 2003; Chirikos, 1998; Rosko, 2001a, 2001b; Rosko and Proenca, 2005; Vitaliano and Toren, 1996).

The Cobb-Douglas assumes that all firms had the same production elasticities, the same scale elasticities, and unitary elasticities of substitution, which quite restrictive and for most studies is trying to compare regulated operators (Coelli et al., 2003).Therefore, translog production technology, which characterizes a flexible functional form, is commonly used by the researchers to avoid modeling errors or/and to get flexibility in the specification of input and output relations without having a-priory assumptions (Rosko and Mutter, 2008).

\section{DATA AND METHODOLOGY}

\subsection{Model Specifications}

In this study six different SFA models are described to estimate the efficiency hospital outpatient care services. The unrestricted model, i.e. Translog TE Model, is describes as Battese and Coelli (1995) specification. The other models are described by imposing some restrictions to the reference models. The Translog TE model is as follows:

$\ln Y_{i t}=\alpha_{0}+\sum_{i=1}^{4} \alpha_{i} \ln x_{i t}+\frac{1}{2} \sum_{i=1}^{4} \sum_{k=1}^{4} \beta_{i k} \ln x_{i t} \ln x_{k t}+\psi_{i} \mathrm{E}_{i k}+v_{i t}-u_{i t}$

Where $i=1, \ldots n$ represent the $\mathrm{i}^{\text {th }}$ hospital and $t=1, \ldots N$ represents the time, $Y_{i t}$ and $X_{i t}$ are respectively the output and inputs of the $\mathrm{i}^{\text {th }}$ firm; $\beta$ is the unknown parameters.

In the unrestricted CE models defined in this study, $V_{i t}$ is the random error assumed to be distributed $V_{i} \sim$ iid $N\left(0, \sigma_{v}^{2}\right)$ and $U_{i t}=U_{i} \exp \left(-\eta(t-T)\right.$ represents the inefficiency of the firm where $U_{i}$ are assumed to be distributed as $U_{i} \sim$ iid $N\left(\mu, \sigma_{U}^{2}\right)$.

In the unrestricted TE models the inefficiency term $U_{i t}$ is assumed to be distributed as $U_{i t} \sim N\left(m_{i t}, \sigma_{u}^{2}\right)$, where $m_{i t}=z_{i t}^{\prime} \delta+e_{i}$ and $z_{i t}^{\prime}$ is a vector of variables which may influence the efficiency of a firm, $\delta$ is a vector of parameters to be estimated.

The other five models are as follows with the restrictions:

- Cobb - Douglas CE-Restricted Model: $\beta_{i k}=0, \eta=0, \mu=0$ and $\delta=0$ 
- Cobb - Douglas CE-Unrestricted Model: $\beta_{i k}=0$ and $\delta=0$

- Cobb - Douglas TE Model: : $\beta_{i k}=0$

- Translog CE-Restricted Model: $\eta=0, \mu=0$ and $\delta=0$

- Translog CE-Unrestricted Model: $\delta=0$

\subsection{Data and Variables}

A panel data on 429 acute-care hospitals for the years, 2012, 2013 and 2104 was used and the sample was consisted of only Turkey $\mathrm{MoH}$ general hospitals including the teaching hospitals. To ensure the data homogeneity, the hospitals which had incomplete input and output data and those with less than 25 beds were excluded from the sample. The description of the variables used in the models are presented in Table (1) with summary descriptive statistics.

\section{Input and Output Variables}

The output variable OUTPAT is the total number of outpatient admissions including emergency service admissions. Four different inputs are used in the models. Three of them represents the labor input used in the hospitals. PHSY is the total number of physicians, including general practitioners, specialist doctors for nonteaching hospitals. Full time employed residents are accounted in PHSY for the teaching hospitals, as the residents also take a part in the production process of the inpatient care services. The other labor input variable ANCl is the total number of ancillary (allied) medical staff. The last labor input variable ADTECH is the total number of the other employees, which consists from administrative and technical staff, including the contracted personnel. The variable BED, being a proxy for capital input, is the total number of the hospital beds.

\section{Control Variables}

The inputs used in the hospitals are heterogeneous in terms of quality. In the production functions, two different control variables are used to capture the input quality differences in both of the models. SPEC is the ratio of specialists in total the number of physicians, and TECH is the technology index of the hospital that represents the use of high-tech diagnostics in the hospitals. The index consists of CT, MRI, CT Simulator, SPECT$\mathrm{CT}, \mathrm{PET}-\mathrm{CT} / \mathrm{PET}$ scanners. Any of those scanners presents in a hospital makes a contribution of one point to the index, thus TECH takes the values between $0-5$ (i.e. if any hospital has all the high-tech diagnostics, then the TECH index value would be 5).

\section{Inefficiency Effects}

SFA hospital efficiency studies also aim to estimate the impact of hospital-specific and environmental factors, which are thought to influence the efficiency of production/cost. In this study, eight different inefficiency effects variables - hospital-specific and environmental characteristics mostly beyond the influence of managerial actions- are defined in the stochastic frontier regression models. Three of them are hospital-specific factors and the rest five variables account the effect of hospital environment on the efficiency.

TEACH is a dummy variable for teaching hospitals. ROLE is an index of hospitals defined on the basis of MoH's hospital role classification. In the MoH's hospital classification scheme, general hospitals are classified into $E, D$, $C, B, A 2$ and $A 1$ groups. The sample of the study does not have any $E$ group hospital. Therefore, the variable ROLE takes to values of $1,2,3,4$, and 5 for the hospital role groups D, C, B, A2 and A1 respectively. The last hospital specific efficiency effects variable EMRG is the rate of inpatient admissions from the emergency

services. This variable represents the effect of demand uncertainty on the technical efficiency scores. DEVINX is a socio - economic development index of the provinces that hospitals are located, calculated in the study of MoD (2013). 
Table 1: Variable Definitions and Summary Statistics

\begin{tabular}{|c|c|c|c|c|c|}
\hline Variable & Definition & Mean & S.D. & Min. & Max. \\
\hline \multicolumn{6}{|l|}{ Outputs } \\
\hline OUTPAT & Total number of outpatient admissions. & 55372.77 & 66375.77 & 518.00 & 375967.00 \\
\hline \multicolumn{6}{|l|}{ Inputs } \\
\hline PHSY & Total Number of Physicians & 86.28 & 126.73 & 4.00 & 872.00 \\
\hline $\mathrm{ANCl}$ & Total Number of Ancillary Medical Staff & 300.27 & 349.95 & 36.00 & 6670.00 \\
\hline ADTECH & $\begin{array}{l}\text { The total number of other employees } \\
\text { (Administrative and technical staff, including the } \\
\text { contracting out personnel ) }\end{array}$ & 291.94 & 302.66 & 23.00 & 1661.00 \\
\hline BED & Total Number of Beds & 213.35 & 227.26 & 25.00 & 1480.00 \\
\hline \multicolumn{6}{|l|}{ Control } \\
\hline \multicolumn{6}{|l|}{ Variables } \\
\hline SPEC & The ratio of specialists in total number of physicians & 0.76 & 0.14 & 0.17 & 1.00 \\
\hline TECH & Technology index of the hospital & 1.29 & 1.09 & 0.00 & 5.00 \\
\hline \multicolumn{6}{|l|}{ Inefficiency } \\
\hline \multicolumn{6}{|l|}{ Effects } \\
\hline TEACH & Dummy variable for teaching hospitals & 0.11 & 0.31 & 0.00 & 1.00 \\
\hline ROLE & Role Index of Hospital (1-5) & 2.79 & 1.16 & 1.00 & 5.00 \\
\hline EMRG & $\begin{array}{l}\text { The rate of inpatient admissions from emergency } \\
\text { services }\end{array}$ & 0.34 & 0.12 & 0.05 & 0.76 \\
\hline DEVINX & $\begin{array}{l}\text { Development index value of hospital location } \\
\text { (Province) }\end{array}$ & 0.65 & 1.51 & -1.73 & 4.52 \\
\hline
\end{tabular}

\section{RESULTS}

In the models, all the production function variables are expressed in deviations from their sample means for ease of simplicity. This is simply a change in the units of measurement and does not change the underlying data; however, it has the advantage that the estimated first-order parameters in the translog function can now be directly interpreted as estimates of the production elasticities, evaluated at the sample means (Coelli et al., 2003:57-59). The maximum-likelihood estimates of the models are given in Table (2). 
Table 2: Model Estimation Results

\begin{tabular}{|c|c|c|c|c|c|c|}
\hline \multirow{3}{*}{ Variables } & \multicolumn{3}{|c|}{ Cobb-Douglas } & \multicolumn{3}{|c|}{ Translog } \\
\hline & \multicolumn{2}{|c|}{ EC Model } & \multirow{2}{*}{ TE Model } & \multicolumn{2}{|c|}{ EC Model } & \multirow{2}{*}{ TE Model } \\
\hline & Restricted & Unrestricted & & Restricted & Unrestricted & \\
\hline Const. & $0.228 *$ & $0.505^{*}$ & $-0.17 *$ & $0.285^{*}$ & $0.425^{*}$ & -0.048 \\
\hline PYSY & $0.300 *$ & $0.265 *$ & $0.49 *$ & $0.318^{*}$ & $0.278 *$ & $0.470^{*}$ \\
\hline $\mathrm{ANCl}$ & $0.076 *$ & $0.107 *$ & 0.01 & $0.137 *$ & $0.145^{*}$ & $0.083^{*}$ \\
\hline OTHER & $0.498 *$ & $0.455^{*}$ & $0.48 *$ & $0.424^{*}$ & $0.397 *$ & $0.442 *$ \\
\hline BED & $-0.061 *$ & -0.004 & $-0.17 *$ & -0.035 & 0.012 & $-0.136^{*}$ \\
\hline PYSY*PYSY & - & - & - & 0.027 & 0.001 & -0.086 \\
\hline PYSY*ANCI & - & - & - & -0.048 & -0.038 & 0.034 \\
\hline PYSY*OTHER & - & - & - & $0.217^{*}$ & $0.224 *$ & $0.286^{*}$ \\
\hline PYSY*BED & - & - & - & $-0.166 *$ & $-0.150 *$ & $-0.254^{*}$ \\
\hline $\mathrm{ANCl} * \mathrm{ANCl}$ & - & - & - & $-0.156 *$ & $-0.138^{*}$ & -0.123 \\
\hline ANCI*OTHER & - & - & - & -0.096 & -0.035 & -0.058 \\
\hline ANCI*BED & - & - & - & $0.313^{*}$ & $0.211 *$ & 0.149 \\
\hline OTHER*OTHER & - & - & - & $-0.250 *$ & $-0.293 *$ & -0.259 \\
\hline OTHER*BED & - & - & - & -0.111 & -0.116 & -0.065 \\
\hline BED*BED & - & - & - & 0.013 & 0.108 & 0.180 \\
\hline SPEC & $0.268^{*}$ & $0.152 *$ & $0.46^{*}$ & $0.229 *$ & $0.238^{*}$ & $0.340^{*}$ \\
\hline $\begin{array}{l}\text { TECH } \\
\text { Inefficiency Effects }\end{array}$ & $-0.020 *$ & $-0.013^{*}$ & -0.02 & $-0.020^{*}$ & -0.011 & $-0.019 *$ \\
\hline$\delta_{0}$ & - & - & $1.21 *$ & - & - & $1.944^{*}$ \\
\hline$\delta_{\text {TEACH }}$ & - & - & 2.72 & - & - & $3.521^{*}$ \\
\hline$\delta_{\text {ROLE }}$ & - & - & -0.70 & - & - & $-0.966^{*}$ \\
\hline$\delta_{\text {EMRG }}$ & - & - & -2.15 & - & - & $-5.997 *$ \\
\hline$\delta_{\text {DEVINX }}$ & - & - & -0.07 & - & - & $-0.199 *$ \\
\hline$\sigma_{U}^{2}$ & $0.227^{*}$ & $0.084 *$ & $0.24 *$ & $0.193 *$ & $0.067^{*}$ & $0.379 *$ \\
\hline$\gamma=\sigma_{u}^{2} /\left(\sigma_{u}^{2}+\sigma_{v}^{2}\right)$ & $0.957^{*}$ & $0.911 *$ & $0.88^{*}$ & $0.951 *$ & $0.894 *$ & 0.919* \\
\hline $\mathrm{Mu}(\mu)$ & - & $0.553^{*}$ & - & - & $0.490^{*}$ & - \\
\hline $\operatorname{Eta}(\eta)$ & - & 0.008 & - & - & $0.035^{*}$ & - \\
\hline Log-likelihood & 517.105 & 600.983 & 112.03 & 566.014 & 637.858 & 146.469 \\
\hline Scale Elasticity $\left(\epsilon_{Y, X}\right)$ & 0.813 & 0.823 & 0.81 & 0.844 & 0.832 & 0.859 \\
\hline
\end{tabular}

* significant at the 0.05 level

The production function parameter estimates are vary between the models, in both magnitude and significance aspects. All the first order parameters of PHYSY, ANCI and OTHER are found to be positive and significant $(p<0.05)$ in all six different models. The parameter of input BED is found to be negative and/or not significant in the models, implying that Bed is not a well-behaved input or there is an excess BED input usage in the production function. Although the estimates of first order parameters, or the output elasticities of the inputs varies between models, the scale elasticity of production, which is the simply the sum of first order parameter, is found to be similar in all models. The estimated scale elasticities in all models suggest that there is diseconomies of scale or negative returns to scale in outpatient service production of hospitals. 
In the Cobb - Douglas TE model all the inefficiency effects variables are not significant. On the other hand all these variables are found to be significant in Translog TE model specification with having same signs compared to Cobb - Douglas TE model. The estimated parameters of the inefficiency effects variables suggest that the efficiency is increases with an increase in hospital ROLE level. The rise in EMRG and DEVINX also contributes hospital efficiency. On the other hand TEACH is negatively associated with efficiency, implying that teaching hospitals are expected to be more inefficient that other hospitals. The variance of inefficiency term of the composite error term $\left(\sigma_{U}^{2}\right)$ is found significant in all models. Gamma, $\left(\gamma=\sigma_{u}^{2} /\left(\sigma_{u}^{2}+\sigma_{v}^{2}\right)\right)$, which shows the ratio of the deviation from frontier caused by inefficiency, is found to be over $90 \%$ and significant in all models.

Table (3) presents the distribution of the mean efficiency scores by selected hospital characteristics. The mean efficiency of all sample hospitals are highest in the Translog-TE model. Both in Cobb - Douglas and Translog production technologies, mean efficiency scores are highest in the TE effects model definitions and lowest in unrestricted EC model specifications. This ranking of mean efficiency scores obtained from different models, does not change with the hospital characteristics.

Table 3: Mean Efficiency Estimations by Hospital Characteristics

\begin{tabular}{|c|c|c|c|c|c|c|}
\hline & \multicolumn{3}{|c|}{ Cobb-Douglas } & \multicolumn{3}{|c|}{ Translog } \\
\hline & \multicolumn{2}{|c|}{ EC Model } & \multirow{2}{*}{$\begin{array}{c}\text { TE } \\
\text { Model }\end{array}$} & \multicolumn{2}{|c|}{ EC Model } & \multirow{2}{*}{$\begin{array}{c}\text { TE } \\
\text { Model }\end{array}$} \\
\hline & Restricted & Unrestricted & & Restricted & Unrestricted & \\
\hline All Sample & 0.683 & 0.563 & 0.862 & 0.708 & 0.598 & 0.881 \\
\hline \multicolumn{7}{|l|}{ Teaching Status } \\
\hline Teaching Hospitals & 0.642 & 0.518 & 0.753 & 0.686 & 0.581 & 0.805 \\
\hline Other Hospitals & 0.688 & 0.568 & 0.875 & 0.710 & 0.600 & 0.890 \\
\hline \multicolumn{7}{|l|}{ Hospital Capacity (Beds) } \\
\hline $25-99$ & 0.653 & 0.540 & 0.850 & 0.692 & 0.582 & 0.881 \\
\hline 100-199 & 0.719 & 0.601 & 0.885 & 0.711 & 0.609 & 0.887 \\
\hline 200-399 & 0.723 & 0.593 & 0.891 & 0.727 & 0.616 & 0.893 \\
\hline $400+$ & 0.670 & 0.540 & 0.828 & 0.722 & 0.604 & 0.858 \\
\hline \multicolumn{7}{|l|}{ ROLE Group } \\
\hline A1 & 0.642 & 0.518 & 0.753 & 0.686 & 0.581 & 0.805 \\
\hline$A 2$ & 0.726 & 0.594 & 0.913 & 0.757 & 0.638 & 0.913 \\
\hline B & 0.746 & 0.623 & 0.900 & 0.739 & 0.632 & 0.899 \\
\hline C & 0.655 & 0.542 & 0.853 & 0.679 & 0.573 & 0.874 \\
\hline$D$ & 0.604 & 0.487 & 0.834 & 0.674 & 0.558 & 0.884 \\
\hline
\end{tabular}

Teaching hospitals are found to be more inefficient than other hospitals in all models. This result is also parallel with the findings of inefficiency effect variable TEACH. The most efficient hospitals are found to have a bed capacity in the range of 200-399. The mean efficiency increases from role groups D to B and A2 (which also related with hospital capacity in terms of beds), than decreases in A1 role group which is the group of Teaching hospitals. The results suggest an optimum hospital capacity should be around 200-400 beds in order to have more efficient outpatient care production.

While different model specifications affect the mean efficiency levels of hospitals, these scores are found to be highly correlated regardless of the model used. As presented in the Table (4) and Table (5), both the Pearson and the Spearman rank-order correlations of means efficiency estimates of different models are highly correlated and all the correlations are significant. The highest correlations are obtained between Cobb Douglas and Translog production technologies when the other restrictions are same, i.e. between Cobb Douglas-TE vs. Translog-TE or between Cobb - Douglas-EC Restricted vs. Translog-EC Restricted. 
Table 4: Pearson Correlation of Efficiency Scores by Different Model Specifications

\begin{tabular}{|c|c|l|c|c|c|c|}
\hline & $\begin{array}{l}\text { Cobb- } \\
\text { Douglas } \\
\text { Restricted }\end{array}$ & $\begin{array}{l}\text { Cobb- } \\
\text { Douglas } \\
\text { Unrestricted }\end{array}$ & $\begin{array}{l}\text { Cobb- } \\
\text { Douglas } \\
\text { TE Effects }\end{array}$ & $\begin{array}{l}\text { Translog } \\
\text { Restricted }\end{array}$ & $\begin{array}{l}\text { Translog } \\
\text { Unrestricted }\end{array}$ & $\begin{array}{l}\text { Translog } \\
\text { TE Effects }\end{array}$ \\
\hline $\begin{array}{c}\text { Cobb-Douglas } \\
\text { Restricted }\end{array}$ & 1.00 &, $982^{* *}$ &, $807^{* *}$ &, $951^{* *}$ &, $956^{* * *}$ &, $779^{* *}$ \\
\hline $\begin{array}{c}\text { Cobb-Douglas } \\
\text { Unrestricted }\end{array}$ & & 1.00 &, $757^{* *}$ &, $927^{* *}$ &, $960^{* *}$ &, $728^{* *}$ \\
\hline $\begin{array}{c}\text { Cobb-Douglas } \\
\text { TE Effects }\end{array}$ & & 1.00 &, $761^{* *}$ &, $726^{* *}$ &, $955^{* *}$ \\
\hline $\begin{array}{c}\text { Translog } \\
\text { Restricted }\end{array}$ & & & 1.00 &, $985^{* *}$ &, $793^{* *}$ \\
\hline $\begin{array}{c}\text { Translog } \\
\text { Unrestricted }\end{array}$ & & & & 1.00 &, $750^{* *}$ \\
\hline $\begin{array}{l}\text { Translog } \\
\text { TE Effects }\end{array}$ & & & & & 1.00 \\
\hline
\end{tabular}

Table 5: Spearman Rank-Order Correlation of Efficiency Scores by Different Model Specifications

\begin{tabular}{|c|r|r|r|r|r|r|}
\hline & $\begin{array}{l}\text { Cobb- } \\
\text { Douglas } \\
\text { Restricted }\end{array}$ & $\begin{array}{l}\text { Cobb- } \\
\text { Douglas } \\
\text { Unrestricted }\end{array}$ & $\begin{array}{l}\text { Cobb- } \\
\text { Douglas } \\
\text { TE Effects }\end{array}$ & $\begin{array}{l}\text { Translog } \\
\text { Restricted }\end{array}$ & $\begin{array}{l}\text { Translog } \\
\text { Unrestricted }\end{array}$ & $\begin{array}{l}\text { Translog } \\
\text { TE Effects }\end{array}$ \\
\hline $\begin{array}{c}\text { Cobb-Douglas } \\
\text { Restricted }\end{array}$ & 1.000 &, $995^{* *}$ &, $888^{* *}$ &, $943^{* *}$ &, $953^{* *}$ &, $878^{* *}$ \\
\hline $\begin{array}{c}\text { Cobb-Douglas } \\
\text { Unrestricted }\end{array}$ & 1.000 &, $871^{* *}$ &, $936^{* *}$ &, $954^{* *}$ &, $861^{* *}$ \\
\hline $\begin{array}{c}\text { Cobb-Douglas } \\
\text { TE Effects }\end{array}$ & & 1.000 &, $824^{* *}$ &, $814^{* *}$ &, $943^{* *}$ \\
\hline $\begin{array}{c}\text { Translog } \\
\text { Restricted }\end{array}$ & & & 1.000 &, $994^{* *}$ &, $899^{* *}$ \\
\hline $\begin{array}{c}\text { Translog } \\
\text { Unrestricted }\end{array}$ & & & & 1.000 &, $880^{* *}$ \\
\hline $\begin{array}{l}\text { Translog } \\
\text { TE Effects }\end{array}$ & & & & & 1.000 \\
\hline
\end{tabular}

\section{CONCLUSION}

The results of this paper suggest that different SFA production function definitions have various effects on model findings. Firstly, the production function or the frontier parameter estimates are considerably affected by model specifications. In different model specifications, the output elasticities of inputs changes both in magnitude and significance. On the other hand, it is found that different model specifications does not change the embowered production characteristics as regardless of the model specification, the scale elasticities estimates suggest that there exist diseconomies of scale or negative returns to scale in outpatient service production in hospitals. This finding is supported by the analysis of mean efficiency distribution along with different hospital characteristics. The teaching hospitals, which have a greater hospital production capacity in terms of bed (also in terms of other inputs) are found to be less efficient than the other hospitals. The optimal hospital capacity to serve outpatient care is found around 200-399 beds.

The other important finding of this paper shows that SFA model specification also affects the mean efficiency scores of hospitals. On the other hand, these scores are highly correlated with respect to model specifications. Therefore, even the SFA specification changes the estimated efficiency score of a single hospital, the rank of the hospital in term of efficiency is not effected by model definitions. 
The results and interpretations of this study is limited within the framework of data set used. The potential weakness of the study is, due to lack of data, output and input variables could not be weighted in terms of case-mix and quality in the analysis. Therefore, the readers should consider the possibility of the results to be biased, before making further comments and statements about these findings.

\section{REFERENCES}

Afriat, S.N. 1972, “Efficiency estimation of production functions”, International Economic Review, 13(3), pp.568-598.

Aigner, D.J. \& Chu, S.F. 1968, “On estimating the industry production function”, American Economic Review, 58(4), pp.826-839.

Aigner, D.J., Lovell, C.A.K. \& Schmidt, P. 1977, "Formulation and estimation of stochastic frontier production function models", Journal of Econometrics, 6(1), pp.21-37.

Atilgan, E. 2015, "The Technical Efficiency of Outpatient Services In Turkish Public Hospitals: A Stochastic Frontier Estimation”, International Healthcare Management Conference (IHMC), Gümüşhane, Turkey (June 2015)

Battese, E. \& Coelli, T. J. 1988, "Prediction of firm level technical inefficiencies with a generalized frontier production function and panel data", Journal of Econometrics, 38, pp.387-399.

Battese, G. E. \& Coelli, T. J. 1992, “Frontier Production Function, technical efficiency and panel data: with application to Paddy Farmers in India", Journal of Productivity Analysis, 3, pp.153-169.

Battese, G. E., Coelli, T. J. \& Colby, T.C. 1989, "Estimation of Frontier Production Functions and the Efficiencies of Indian Farms Using Panel Data from ICRISAT's Village Level Studies", Journal of Quantitative Economics, 5(2), pp.327-48.

Battese, G.E. \& Coelli, T. J. 1995, "A model for technical inefficiency effects in a stochastic frontier production function for panel data", Empirical Economics, 20, pp.325-332.

Carey, K. 2003, "Hospital cost efficiency and system membership", Inquiry, 40, pp.25-38.

Chirikos, T. \& Sear, A. 2000, "Measuring hospital inefficiency: A comparison of two approaches", Health Services Research, 34, pp.13891408.

Chirikos, T. 1998, "Identifying efficiently and economically operated hospitals: The prospects and pitfalls of applying frontier regression techniques", Journal of Health Politics, Policy and Law, 23, pp.879-904.

Chirikos, T. 1998/1999, "Further evidence that hospital production is inefficient". Inquiry, 35, pp.408-416.

Coelli, T. J., Estache, A., Perelman, S. \& Trujillo, L. 2003, "A primer on efficiency measurement for utilities and transport regulators", WBI Development Studies.

Coelli, T. J., Rao, D. S. P., O'Donnell, C. J. \& Battese, G. E. 2005, "An introduction to efficiency and productivity analysis", Springer Science \& Business Media.

Deily, M. \& McKay, N. 2005, "Comparing high- and low-performing hospitals using risk-adjusted excess mortality and cost inefficiency", Health Care Management Review, 30, pp.347-360.

Deily, M. \& McKay, N. 2006, “Cost inefficiency and mortality rates in Florida hospitals", Health Economics, 15, pp.419-431.

Deily, M., McKay, N. \& Dorner, F. 2001, “Exit and inefficiency: The effects of ownership type”, Journal of Human Resources, 35, pp.734-747.

Folland, S. \& Hofler, R. 2001, "How reliable are hospital efficiency estimates? Exploiting the dual to homothetic production", Health Economics, 10, pp.683-698.

Greene, W. H. 1980a, "Maximum likelihood estimation of econometric frontier functions", Journal of Econometrics, 13(1), pp.27-56.

Greene, W. H. 1980b, “On the estimation of a flexible frontier production model”, Journal of Econometrics, 13(1), pp.101-115.

Kumbhakar, S. \& Lovell, C. 2000, "Stochastic Frontier Analysis", Cambridge: Cambridge University Press.

Li, T. \& Rosenman, R. 2001, "Cost efficiency in Washington hospitals: A stochastic frontier approach using panel data", Health Care Management Science, 4, pp.73-81.

Linna, M. 1998, "Measuring hospital cost efficiency with panel data models", Health Economics, 7 (5), pp.415-427.

McKay, N., Deily, M. \& Dorner, F. 2002/2003, "Ownership and changes in hospital inefficiency, 1986-1991", INQUIRY: The Journal of Health Care Organization, Provision, and Financing, 39, pp.388-399.

Meeusen, W. \& Van den Broeck, J. 1977, "Efficiency estimation from Cobb-Douglas production functions with composed error", International Economic Review, 18(2), pp.435-444. 
Pitt, M. M. \& Lee, L. F. 1981, "The measurement and sources of technical inefficiency in the Indonesian weaving industry", Journal of Development Economics, 9, pp.43-64.

Richmond, J. 1974, "Estimating the Efficiency of Production", International Economic Review, 15(2), pp.515-521.

Rosko, M. \& Chilingerian, J. 1999, “Estimating hospital inefficiency: Does case mix matter?” Journal of Medical Systems, 23, pp.57-71.

Rosko, M. \& Mutter, R. 2008, "Stochastic Frontier Analysis of Hospital Inefficiency: A Review of Empirical Issues and an Assessment of Robustness", Medical Care Research and Review, 65(2), pp.131-166.

Rosko, M. \& Proenca, J. 2005, “Impact of network and system use on hospital X-inefficiency", Health Care Management Review, 30, pp.6979.

Rosko, M. 1999, “Impact of internal and external environmental pressures on hospital inefficiency", Health Care Management, Science, 2, pp.64-78.

Rosko, M. 2001a, "Cost efficiency of U.S. hospitals: A stochastic frontier approach", Health Economics, 10, pp.539-551. doi: 10.1002/hec.607

Rosko, M. 2001b, "Impact of HMO penetration and other environmental factors on hospital X-inefficiency", Medical Care Research and Review, 58, pp.430-454.

Stevenson, R. E. 1980, "Likelihood functions for generalized stochastic frontier estimation”, Journal of Econometrics, 13(1), pp.57-66.

Vitaliano, D. \& Toren, M. 1996, “Hospital cost and efficiency in a regime of stringent regulation”, Eastern Economic Journal, 22, pp.161-173.

Winsten, C.B. 1957, “Discussion on Mr. Farrell's Paper”, Journal of the Royal Statistical Society: Series A (General), 120(3), pp.282-284.

Worthington, A. 2004, "Frontier efficiency measurement in health care: a review of empirical techniques and selected applications", Medical Care Research and Review, 61, pp.135-170.

Zuckerman, S., Hadley, J. \& lezzoni, L. 1994, "Measuring hospital efficiency with frontier cost functions", Journal of Health Economics, 13, pp.255-280. 